\title{
Pathophysiology and molecular aspects of diffuse large B-cell lymphoma
}

\author{
Gisele Rodrigues Gouveia \\ Sheila Aparecida Coelho Siqueira \\ Juliana Pereira
}

Hospital das Clínicas da Faculdade de Medicina, Universidade de São Paulo - USP São Paulo, SP, Brazil
Conflict-of-interest disclosure:

The authors declare no competing financial interest

Submitted: 4/13/2012

Accepted: 9/28/2012

\section{Corresponding author:}

Gisele Rodrigues Gouveia

Immunopathology Laboratory - Hospital das Clínicas da Faculdade de Medicina da Universidade de São Paulo - HCFMUSP Av. Dr. Enéas Carvalho de Aguiar, 155,

$1^{\circ}$ Andar - Cerqueira César

05403-000 - São Paulo, SP, Brazil

Phone: $55113061-5544$

gisele.gouveia@usp.br

www.rbhh.org or www.scielo.br/rbhh
Diffuse large B-Cell lymphoma is the most common subtype of non-Hodgkin lymphoma in the West. In Brazil, it is the fifth cause of cancer, with more than 55,000 cases and 26,000 deaths per year. At Hospital das Clínicas da Faculdade de Medicina da Universidade de São Paulo - HCFMUSP, diffuse large B-Cell lymphoma represents $49.7 \%$ of all non-Hodgkin lymphoma cases. Initially, the classification of non-Hodgkin lymphoma was based on morphology, but advances in immunology and molecular medicine allowed the introduction of a biological classification for these diseases. As for other cancers, non-Hodgkin lymphoma involves patterns of multifactorial pathogenesis with environmental factors, as well as genetic, occupational and dietary factors, contributing to its development. Multiple lesions involving molecular pathways of $B$-cell proliferation and differentiation may result in the activation of oncogenes such as the BCL2, BCL6, and MYC genes and the inactivation of tumor suppressor genes such as p53 and INK4, as well as other important transcription factors such as OCT-1 and OCT-2. A dramatic improvement in survival was seen after the recent introduction of the anti-CD20 monoclonal antibody. The association of this antibody to the cyclophosphamide, hydroxydaunorubicin, oncovin and prednisolone (CHOP) regimen has increased overall survival of diffuse large B-Cell lymphoma and follicular lymphoma patients by 20\%. However, $50 \%$ of all diffuse large B-Cell lymphoma patients remain incurable, creating a demand for more research with new advances in treatment. Thus, it is important to know and understand the key factors and molecular pathways involved in the pathogenesis of diffuse large B-Cell lymphoma.

Keywords: Lymphoma; Lymphoma, B-cell/physiopathology; Prognosis; Oncogenes; Genes, tumor suppressor

\section{Introduction}

Non-Hodgkin lymphomas (NHLs) occur as a result of an expansion and progressive accumulation of a mature single clone of lymphocytes ${ }^{(1)}$. The most common subtype, diffuse large B-Cell lymphoma (DLBCL), is characterized by a diffuse proliferation of large and mature B-cells. These cells usually are larger than, or equal to, twice the normal size of macrophages or lymphocytes ${ }^{(2)}$.

DLBCL is clinically and biologically heterogeneous, aggressive, and includes several subtypes $^{(2)}$. It may arise as primary or de novo, or may result from a transformation of an indolent lymphoma ${ }^{(3)}$. The majority of cases occur in lymph nodes with $40 \%$ in extranodal sites $^{(4)}$. These cases occur most frequently in the gastrointestinal tract, but may appear in any organ, including the skin, central nervous system (CNS), bone marrow (BM), salivary gland, lung, kidney, and liver ${ }^{(5,6)}$. Bone marrow involvement is found in $11 \%$ to $27 \%$ of all cases but rarely infiltrates the peripheral blood ${ }^{(7)}$.

Initially, the classification of NHL was based on morphological features of the malignant cell, but today it is also based on immunological and molecular data. Thus, complementary techniques of immunohistochemistry, flow cytometry, cytogenetic, polymerase chain reaction, and gene signature by microarray are used.

According to the World Health Organization $(\mathrm{WHO})^{(7)}$, DLBCLs may be subdivided into morphological variants.

The centroblastic variant presents medium to large lymphoid cells, vesicular nuclei, fine chromatin and scant cytoplasm. In some cases, it may feature cells with multiple lobules and more than $90 \%$ of immunoblasts with a marked polymorphism. Shahi \& Manga ${ }^{(3)}$ observed one to three prominent basophilic nucleoli in some cases. Indeed, they suggest that this variant may present two morphological subtypes. The first is called the monomorphic subtype, with almost $100 \%$ of centroblasts, and the second, comprising of $10 \%$ of centroblasts and less than $90 \%$ of immunoblasts, the polymorphic subtype ${ }^{(7)}$.

In the immunoblast subtype, the cell population comprises more than $90 \%$ of immunoblasts. It is characterized by cells with a single central nucleus and a basophilic and variable cytoplasm, but less than $10 \%$ of centroblasts. Immunophenotyping and clinical characteristics are essential to differentiate it from the plasmablastic variant of DLBCL. According to Shahi \& Manga ${ }^{(3)}$, the plasmablastic variant represents $10 \%$ of all DLBCL and is more common in immunosuppressed patients, especially those with HIV ${ }^{(7)}$. 
DLBCL rich in T-cells and histiocytes is formed by a high quantity of reactive T-cells with or without histiocytes, and less than $10 \%$ of large neoplastic B-cells. The growth pattern of this subtype of DLBCL is predominantly diffuse, with fine reticular fibers in the tumor microenvironment. Immunophenotyping is essential to differentiate it from classic Hodgkin lymphoma (cHL). This variant is rare and presents a worse prognosis ${ }^{(6)}$.

The anaplastic subtype is characterized by oval or polygonal cells with pleomorphic nuclei. Cells may take on a cohesive growth pattern, such as that found in carcinoma, or a sinusoidal growth pattern. The malignant cells express the CD30 (ki-1) antigen and the main differential diagnoses are Hodgkin's lymphoma (HL) and T-cell NHL that express CD30 ${ }^{(6)}$.

Primary Central Nervous System (CNS) DLBCL represents all cases of intra-cerebral or intraocular lymphomas and corresponds to less than $1 \%$ of NHL cases and 2-3\% of all brain tumors. The average age at incidence is 60 years. The clinical characteristics are neurological disorders as observed in $80 \%$ of patients. Neuropsychiatric symptoms are observed in 20 to $30 \%$ and high intracranial pressure may also be observed ${ }^{(7)}$.

Primary cutaneous DLBCL (leg type) represents $4 \%$ of all primary cutaneous DLBCL, and $20 \%$ of all primary cutaneous B-cell lymphomas. It occurs in elderly women in the seventh decade of life. It usually affects the legs but in 10 to $15 \%$ may occur in other sites ${ }^{(7)}$.

Epstein-Barr Virus (EBV)-positive DLBCL of the elderly is a clonal proliferation of large B-cells. Its incidence is more common after the fifth decade of life and in patients with no previous immunodeficiency. Other rare subtypes of DLBCL are lymphomatoid granulomatosis and primary effusion lymphoma.

DLBCL associated with chronic inflammation is a lymphoid neoplasm associated with EBV. The mean time elapsed between chronic inflammation and lymphoma is 10 years. Diagnosis occurs between the fifth and eighth decades of life with a median age of 65 years. The most common sites of involvement are the pleural cavity, femur and periarticular tissue. The tumor mass is greater than $10 \mathrm{~cm}$ in more than half of all cases. There is direct invasion of adjacent structures, but the tumor is often limited to the thoracic cavity until diagnosis. About $70 \%$ of patients present clinical stage $\mathrm{I}$ or $\mathrm{II}^{(7)}$.

Unclassifiable B-cell lymphomas with features intermediate between DLBCL and Burkitt Lymphoma (BL) are aggressive lymphomas that, owing to their clinical and biological characteristics, may not be included in one of these two categories. In most cases, morphological characteristics are intermediate, with cells smaller than in typical DLBCL and larger than in typical BL but the phenotype of cells is compatible with BL. This lymphoma is rare in adults and more than half the patients show extranodal disease, such as bone marrow and peripheral blood involvement ${ }^{(7)}$.

B-cell lymphomas with features intermediate between DLBCL and cHL are common in young males (20 to 40 years). Etiology is unknown and the most common site of involvement is the mediastinum, with or without the involvement of lymph nodes ${ }^{(7)}$.

Studies of gene expression patterns divided DLBCL into three subtypes that are morphologically indistinguishable: activated B-cell DLBCL, germinal center DLBCL, and primary mediastinal B-cell lymphoma. They express distinct genes that have been found at different stages of B-cell differentiation ${ }^{(8)}$.

\section{Epidemiology}

DLBCL represents $80 \%$ of all aggressive lymphomas ${ }^{(3)}$ and 30 to $40 \%$ of all NHL cases in the West and are one of the most frequent in developing countries ${ }^{(2)}$. At the Hospital das Clínicas da Faculdade de Medicina da Universidade de São Paulo HCFMUSP, DLBCL represents $49.57 \%$ of all NHL $\operatorname{cases}^{(9)}$. NHL is the fifth most common type of cancer in Brazil, with an incidence of 55,000 cases and over 26,000 deaths per year ${ }^{(10)}$. In São Paulo, in 1998, the incidence of NHL cases was 12.2/100 thousand inhabitants ${ }^{(11)}$. Likewise, DLBCL is the most common lymphoma in adults (31\%), followed by follicular lymphoma (FL) ${ }^{(12-14)}$. The median age at incidence is 70 years and it predominates in males $(55 \%)^{(12)}$.

According to Friedberg ${ }^{(12)}$, the incidence of DLBCL has been increasing by 3 to $4 \%$ per year in both genders, in white and non-white populations, and in all age groups, except for adolescents. Factors such as more sensitive diagnostic techniques, changes in the classification of lymphoproliferative disorders and, particularly, the increase of NHL in HIV patients have contributed to the escalation in the incidence of this disease.

Environmental factors, as well as genetic, occupational and dietary factors, may have contributed to the development of $\mathrm{NHL}^{(15)}$. NHLs are associated with chronic inflammatory diseases such as Sjögren syndrome, celiac disease and rheumatoid arthritis. Indeed, infectious agents are also related to the pathogenesis, but no greater incidence of NHL has been found in individuals who handle organic solvents, organophosphates, benzene or carbon tetrachloride ${ }^{(16)}$.

In DLBCL, factors such as ultraviolet radiation, pesticides, and hair dye are potentially associated with higher risk. In addition, immunosuppression, especially related to HIV, is a risk factor and it may be associated with Epstein-Barr virus ${ }^{(13)}$.

\section{Pathophysiology}

DLBCL arises from mature B-cells at different stages of differentiation. Several gene mutations promote changes in $\mathrm{B}$-cells, changing the gene expression and promoting a neoplastic transformation (Figure 1) ${ }^{(17)}$.

During B lymphocyte ontogeny, after leaving the bone marrow, those cells travel to secondary lymphoid tissues where they will find their respective antigens promoting the development of secondary follicles. An antigen-dependent phase of B-cell development occurs at this site. In the germinal center of the secondary follicle, these lymphocytes are transformed into centroblasts that have a high rate of proliferation, while frequent and continuous somatic mutations of genes of the immunoglobulin variable chain occur, promoting maturation and differentiation into centrocytes and subsequently into plasma cells or in memory B-cells ${ }^{(17)}$. In the germinal center, the $B C L 2$ gene expression is usually down regulated and $B C L 6$ is hyperexpressed ${ }^{(8,17)}$. 


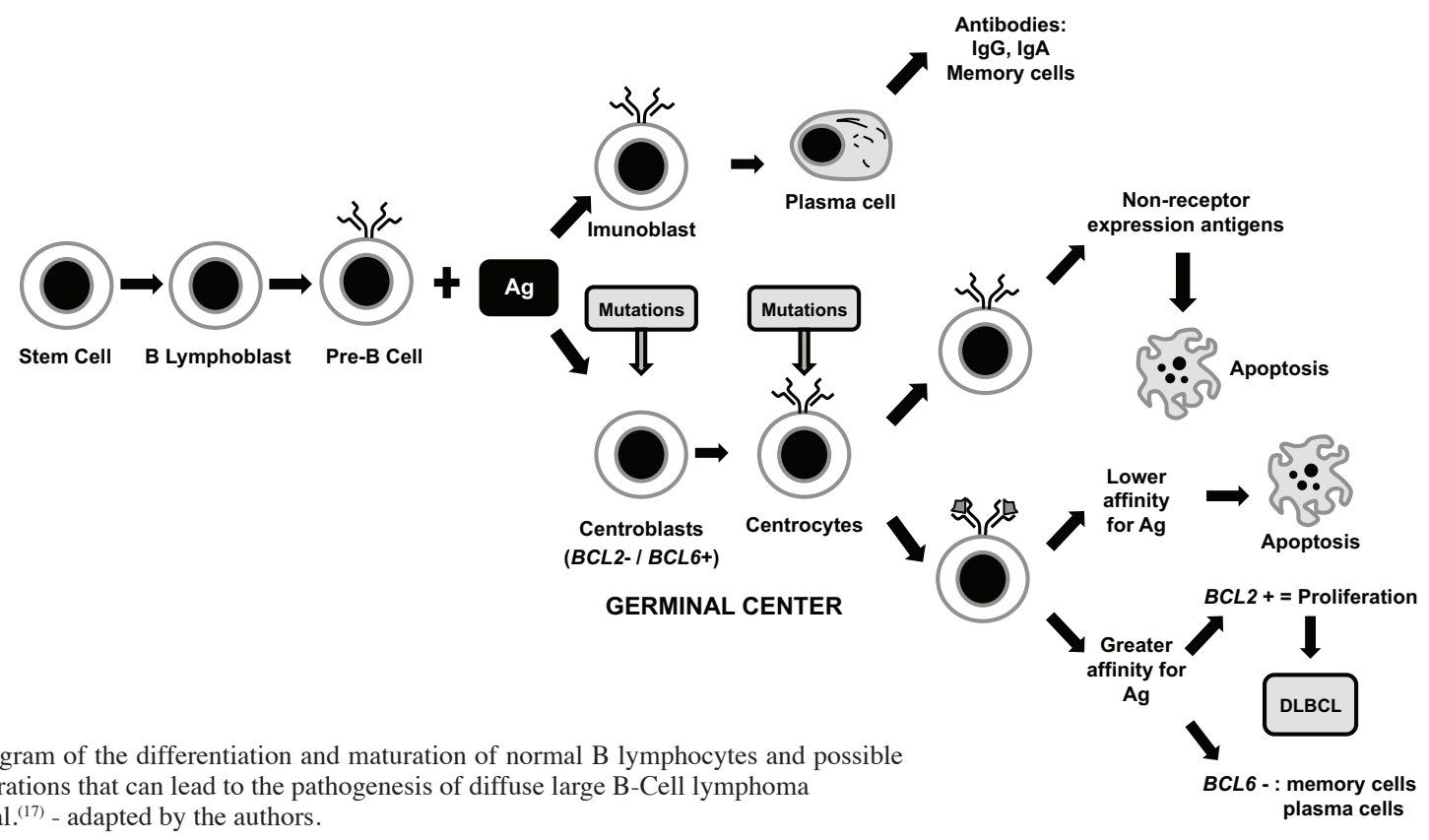

Figure 1 - Diagram of the differentiation and maturation of normal B lymphocytes and possible molecular alterations that can lead to the pathogenesis of diffuse large B-Cell lymphoma Guilherme et al. ${ }^{(17)}$ - adapted by the authors.

\section{Molecular Events Involved in DLBCL Pathogenesis}

Proto-oncogenes are important to control cell proliferation. However, when inappropriately activated by genetic abnormalities such as chromosomal translocations, gene mutations or amplification, the cells may acquire a malignant transformation. In contrast, tumor suppressor genes promote cell differentiation and decreased cell proliferation. In the malignant transformation process, oncogene activation and inhibition of the tumor suppressor genes usually occur. Similar to other cancers, the pathogenesis of DLBCL occurs in multiple steps that results in the development of the disease (Figure 2) ${ }^{(1,14,18)}$.

As previously described, the B lymphocyte ontogeny occurs in the bone marrow and in peripheral lymphoid tissues and depends on various genetic recombinations that function as points of vulnerability, subject to deleterious events that affect the immune system and the individual. However, in most cases, protective mechanisms surmount these disorders and the physiological homeostasis is preserved resulting in the formation of immunologically perfect B-cells. Examples of important genetic events that are essential in the development of B-cells are the recombination of genes encoding the heavy Ig chains driven by the $R A G 1$ and $R A G 2$ genes, and the hypermutation of variable regions of the genes responsible for encoding the light Ig chains and the switch of the Ig $\operatorname{class}^{(1,8)}$.

The BCL6 gene is one of the most frequently affected in DLBCL. On the other hand, the $t(14 ; 18)$, which juxtaposes the $B C L 2$ oncogene located on chromosome 18 to the promoter region of the gene encoding the heavy Ig chain on chromosome 14 , results in an overexpression of the BCL2 protein, a condition found in $15 \%$ to $30 \%$ of all DLBCL cases ${ }^{(14,19-22)}$.

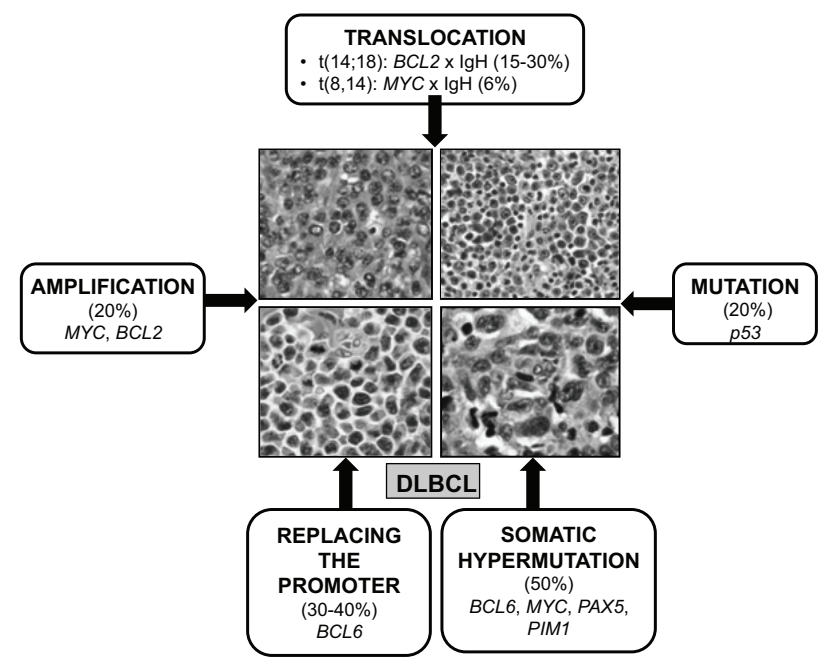

Figure 2 - Main genetic lesions that occur in the pathogenesis of diffuse large B-Cell lymphoma (DLBCL) and their respective frequencies. Lossos $^{(14)}$ - adapted by the authors.

\section{Main oncogenes involved in the pathogenesis of DLBCL}

\section{BCL2}

The $B C L 2$ gene, which encodes an anti-apoptotic protein located in the outer membrane of the mitochondria and cytoplasm, plays an important role in the pathogenesis of NHL. This protein is involved in mechanisms related to resistance to chemotherapy ${ }^{(23-25)}$. Amen et al. ${ }^{(26)}$ demonstrated higher overall survival and disease-free survival in DLBCL with no BCL2 and Cyclin D2 expression. However, other authors have demonstrated 
a negative effect of the expression of BCL2 only in the subgroup of activated B-cell DLBCL $22-25,27)$.

\section{BCL6 Gene}

The BCL6 gene is a proto-oncogene located on chromosome $3 q 27$ expressed on normal B-cells in the germinal center ${ }^{(28-30)}$. The BCL6 protein blocks genes involved in cell cycle progression and response to DNA damage $\mathrm{e}^{(8)}$. Chromosomal translocations involving the BCL6 gene occur in $30 \%$ to $40 \%$ of tumors and arise from disorders in the sequence in the promoter region of DNA. The role of the BCL6 gene in the pathogenesis of DLBCL was recently elucidated. Alterations in BCL6 protein expression may cause failure in cell differentiation and continuous activation and cell proliferation. Consequently, it promotes a higher cell survival and genetic instability that contributes to malignant transformations ${ }^{(14)}$.

Main tumor suppressor genes related to the pathogenesis and prognosis of DLBCL

\section{p53 Gene}

The p53 gene is located on chromosome 17, encoding a nuclear phosphoprotein $\mathrm{p} 53$. This protein acts by regulating the DNA transcription, cell proliferation and apoptosis ${ }^{(28)}$. Sixty percent of malignant human tumors and $30 \%$ of B-cell lymphomas present the p53 mutation. Most of them occur in exons 5 and 9 and affect their function in the control of the DNA repair. Patients with absent or mutated $p 53$ present more aggressive disease and worse prognosis ${ }^{(31)}$. Some studies have suggested that $p 53$ may be inactivated by the BCL6 gene during the genesis of lymphoma ${ }^{(14)}$.

\section{MYC Gene}

MYC gene mutations may occur in regions of exons and introns $^{(14)}$. Recombination of the $M Y C$ gene with other genes can be found in $2 \%$ to $16 \%$ of DLBCL cases, especially in extranodal lymphomas. It is associated with lower complete remission and worse overall survival rates ${ }^{(12)}$.

Main transcription factors in the pathogenesis and prognosis of DLBCL

The differentiation and proliferation of B-cells are controlled by transcription factors ${ }^{(32)}$. Two of these factors are the OCT-1 and OCT-2 proteins that belong to the POU family and are linked to genes involved in B-cell regulation ${ }^{(33)}$.

The OCT-2 protein is little expressed in pre-B-cells, T-cells, myelomonocytic and epithelial cells. However, it is strongly expressed in mature B-cells. On the other hand, the OCT-1 protein is highly expressed in pre-B-cells, suggesting that it may be involved in the early phase of B-cell development ${ }^{(33)}$.

Recent studies have demonstrated, through the RNA interference technique, that OCT factors influence the survival of cells in lymphomas with the $\mathrm{t}(14 ; 18)$. A positive correlation was found between OCT, BOB 1 and BCL2 expressions. OCT-2 activates the promoter of the BCL2 gene and is involved in the malignant transformation in B lymphomas. The low expressions of OCT-1, OCT-2 and BOB1 are inversely proportional to apoptosis ${ }^{(34)}$.

\section{Conclusions}

DLBCL is the most common subtype of NHL and only 40 to $50 \%$ of all adult patients are cured. Knowledge of the malignant cell biology has promoted an increase in the overall survival rate. However, this knowledge is incipient and many other studies of the gene expression of malignant cells and the tumor microenvironment are necessary. The advance in molecular biology techniques has been essential and its continuous improvement is fundamental to achieve maximum understanding of the biology. The final goal is to translate the knowledge of the biology of DLBCL into new options of therapy to try to improve patient survival.

\section{References}

1. Klumb CE. Biologia e patogênese dos linfomas não Hodgkin de origem B na infância: uma revisão. Rev Bras de Cancerol. 2001;43(3):291-301.

2. World Health Organization. Pathology and genetics of tumours of haematopoietic and lymphoid tissues. Lyon: International Agency for Research on Cancer; 2001

3. Shahi PK, Manga GP. Linfoma B difuso de células grandes. Med Clin (Barc). 2006;127(1):17-21

4. Harris NL, Jaffe ES, Stein H, Banks PM, Chan JK, Claery ML, et al A revised European-American classification of lymphoid neoplasms: a proposal from the International Lymphoma Study Group. Blood 1994;84(5):1361-92. Comment in: Blood. 1994;84(5):1359-60; Blood. 1995;85(3):857-60; Blood. 1996;88(6):2361-2; Blood 1995;85(7):1972-4; Blood. 1996;87(1):412-3 .

5. Pettit CK, Zukerberg LR, Gray MH, Ferry JA, Rosenberg AE, Harmon DC, et al. Primary lymphoma of bone. A B-cell neoplasm with a high frequency of multilobated cells. Am J Surg Pathol. 1990;14(4):329-34.

6. Van Baarlen J, Schuurman HJ, Van Unnik JA. Multilobated non-Hodgkin's Lymphoma. A clinicopathologic entity. Cancer. 1988;61(7):1371-6.

7. World Health Organization. WHO Classification of tumours of haematopoietic and lymphoid tissues. Lyon: International Agency for Research on Cancer; 2008.

8. Lenz G, Staudt LM. Aggressive lymphomas. N Engl J Med. 2010;362(15):1417-29.

9. Gouveia GR, Siqueira SA, Chamone DA, Pereira J. Prevalence of non-Hodgkin Lymphomas in São Paulo, Brazil. Rev Bras Hematol Hemoter. 2011;33(4):315-22.

10. Bigni R. Linfoma não-Hodgkin [Internet]. Rio de Janeiro: Instituto Nacional do Câncer; 2004. [cited 2004 Jun 29]. Available from: http://www.inca.gov.br/conteudo_view.asp?id=457

11. Mirra AP, Latorre MR, Veneziano DR. Incidência de câncer no município de São Paulo, Brasil: 1997-1998. Mortalidade de câncer no município de São Paulo, Brasil, tendência no período de 1969-1998 [Internet] Brasília: Ministério da Saúde, 2001. [cited 2010 Apr 21] . Available from: http://www.fsp.usp.br/rcsp/img/arquivos/rcsp_2001.pdf

12. Gonçalves EM. Linfomas difusos de grandes células B - factores de prognóstico clínicos [dissertation]. Porto: Universidade do Porto; 1999.

13. Friedberg JW. Rituximabe for early-stage diffuse large B-cell lymphoma. Lancet Oncol. 2006;7(5):357-9. Comment In: Lancet Oncol. 2006;7(5):379-91. 
14. Lossos IS. Molecular pathogenesis of diffuse large B-cell lymphoma. J Clin Oncol. 2005;23(26):6351-7.

15. Araújo LH, Victoriano AP, Melo AC, Assad DX, Lima DS, Alencar DR, et al. Linfoma não-Hodgkin de alto grau: revisão de literatura. Rev Bras Cancerol. 2008;54(2):175-83.

16. Colleoni GW, Inaoka RJ. Linfomas não-hodgkin: aspectos clínicos, prognósticos e terapêuticos na era do rituximabe. Diálogo Científico. 2007; (Nov/Dec):19-22.

17. Guilherme RS, Caputto LZ, Fonseca AL, Pereira J, Fonseca FL. Exames laboratoriais complementares indicados no apoio ao diagnóstico do Linfoma Difuso de Grandes Células B (LDGCB). Arq Bras Ciênc Saúde. 2008;33(3):186-94.

18. Junqueira LC, Carneiro J. Biologia celular e molecular. $8^{\text {th }}$. ed. Rio de Janeiro: Guanabara Koogan; 2005.

19. Akagi T, Kondo E, Yoshino T. Expression of Bcl-2 protein and Bcl-2 mRNA in normal and neoplastic lymphoid tissues. Leuk Lymphoma. 1994;13(1-2):81-7.

20. Kotliar N, Koziner B. Aplicaciones de lareaccion em cadena de lapolimerasia (PCR) em oncohematologia. Medicina (B Aires). 1995;55(2):159-66.

21. Meier VS, Rufle A, Gudat F. Simultaneous evaluation of T- and B-cell clonality, $\mathrm{t}(11 ; 14)$ and $\mathrm{t}(14 ; 18)$, in a single reaction by a four-color multiplex polymerase chain reaction assay and automated high-resolution fragment analysis. Am J Pathol. 2001;159(6):2031-43.

22. Kramer MH, Hermans J, Parker J, Krol AD, Kluin-Nelemans JC, Haak $\mathrm{HL}$, et al. Clinical significance of bcl2 e p53 protein expression in diffuse large B-cell lymphoma: a population-based study. J Clin Oncol. 1996;14(7):2131-8

23. Abd El-Hameed A. De novo nodal diffuse large B-cell lymphoma: identification of biologic prognostic factors. J Egypt Natl Canc Inst. 2005;17(1):20-8.

24. Iqbal J, Neppalli VT, Wright G, Dave BJ, Horsman DE, Rosenwald A, et al. BCL2 expression is a prognostic marker for the activated B-cell-like type of diffuse large B-cell lymphoma. J Clin Oncol. 2006;24(6):961-8.
25. Wu G, Keating A. Biomarkers of potential prognostic significance in diffuse large B-cell lymphoma. Cancer. 2006;106(2):247-57.

26. Amen F, Horncastle D, Elderfield K, Banham AH, Bower M, Macdonald $\mathrm{D}$, et al. Absence of cyclin-D2 and Bcl-2 expression within the germinal centre type of diffuse large B-cell lymphoma identifies a very good prognostic subgroup of patients. Histopathology. 2007;51(1):70-9.

27. Piris M, Brown DC, Gatter KC, Mason DY. CD30 expression in non-Hodgkin's lymphoma. Histopathology. 1990;17(3):211-8.

28. Barra MB. O uso da Imunohistoquímica no diagnóstico: indicações e limitações. Rev AMRIGS. 2006;50(2):173-84

29. Van Imhoff GW, Boerma EG, Holt BV, Schuuring E, Verdonck LF, Kluin-Nelemans $\mathrm{HC}$, et al. Prognostic impact of germinal center-associated proteins and chromosomal breakpoints in poor-risk diffuse large B-cell lymphoma. J Clin Oncol. 2006;24(25):4135-42.

30. Hallack Neto AE. Estudo observacional do prognóstico e terapêutica dos portadores de linfoma difuso de células B e de IPIa de risco intermediário-alto e intermediário [thesis]. São Paulo: Universidade de São Paulo; 2008.

31. Cavalcanti Júnior GB, Klumb CE, Maia RC. P53 e as hemopatias malignas. Rev Bras Cancerol. 2002;48(3):419-27.

32. McCune RC, Syrbu SI, Vasef MA. Expression profiling of transcription factors Pax-5, Oct-1, Oct-2, BOB.1 and PU.1 in Hodgkin's and nonHodgkin's lymphomas: a comparative study using high throughput tissue microarrays. Mod Pathol. 2006;19(7):1010-8.

33. Sáez AI, Artiga MJ, Sánchez-Beato M, Sánchez-Verde L, García JF, Camacho FI, et al. Analysis of octamer-binding transcription factors Oct 2 and Oct1 and their coactivator BOB.1/OBF.1 in lymphomas. Mod Pathol. 2002;15(3):211-20

34. Heckman CA, Duan H, Garcia PB, Boxer LM. Oct transcription factors mediate $\mathrm{t}(14 ; 18)$ lymphoma cells survival by directly regulating bcl-2 expression. Oncogene. 2006;25(6):888-98. 